\title{
Anaphylactic Reaction to Tc-99m Macrosalb
}

\author{
Nanno Schreuder ${ }^{1,2} \cdot$ Quincy de Hoog ${ }^{1} \cdot$ Wouter van der Bruggen ${ }^{3}$. Eugène P. van Puijenbroek ${ }^{1,4}$
}

Published online: 5 March 2019

(c) The Author(s) 2019

\begin{abstract}
A 49-year-old woman developed an anaphylactic reaction to Tc-99m macrosalb used for pulmonary scintigraphy. The patient received an intravenous injection of Tc-99m macrosalb $120 \mathrm{MBq}$, containing macroaggregates of human albumin $0.14 \mathrm{mg}$. Within 1 min she developed itching all over her body, an itching throat and dyspnoea. This was followed by urticaria and facial oedema. She was diagnosed with an anaphylactic shock. The patient received clemastine and prednisone, and fully recovered after release from the hospital. According to the Naranjo assessment algorithm, the relationship between the allergic reaction and the administration of Tc-99m macrosalb should be considered as 'probable'.
\end{abstract}

\section{Key Points}

Anaphylactic reactions to Tc-99m macrosalb may occur. Although rare, the possibility of such a reaction must be anticipated.

Healthcare professionals should check whether a patient has had a previous severe reaction to Tc-99m macrosalb.

Medical personnel should be prepared for these kinds of reactions, and suitable protocols for managing and treating anaphylactic reactions should be readily available.

\section{Introduction}

Tc-99m macrosalb (macro-aggregated albumin; MAASOL ${ }^{\circledR}$, the Netherlands) is a diagnostic radiopharmaceutical used in lung perfusion scans and venoscintigraphy. The

Nanno Schreuder

n.schreuder@rug.nl

1 Groningen Research Institute of Pharmacy, Unit of PharmacoTherapy, Epidemiology and Economics, University of Groningen, Antonius Deusinglaan 1, Groningen, The Netherlands

2 GE Healthcare Radiopharmacy Zwolle, Dokter Spanjaardweg 1A, Zwolle, The Netherlands

3 Department of Nuclear Medicine, Slingeland Ziekenhuis, Kruisbergseweg 25, Doetinchem, The Netherlands

4 Netherlands Pharmacovigilance Centre Lareb, Goudsbloemvallei 7, 's Hertogenbosch, The Netherlands radiopharmaceutical is reconstituted using a kit containing human serum albumin [1]. Single or multiple injections with Tc-99m macrosalb may be associated with chest pains, rigor and collapse. The frequency of adverse drug reactions in the use of radiopharmaceuticals in general is low, according to the literature. It is generally assumed that the frequency ranges from 2.1 to 6 per 100,000 injections of radiopharmaceuticals [2, 3]. Although it includes a warning about the possibility of hypersensitivity, according to the Summary of Product Characteristics the frequency of hypersensitivity reactions is not known.

We report a case of a suspected severe Tc-99m macrosalb-induced anaphylaxis. We also completed a literature search through PubMed and MEDLINE, without language restrictions, applying no year limits and therefore extended as far back as the late 1940s. The search terminology included both the following index terms and free-text words: 'radiopharmaceutical' or 'radioisotope' combined with 'adverse effects', 'adverse reactions', 'adverse events', or 'side effects'. A filter for the search was applied to exclude animal-only studies. The search was completed in July 2018.

Only three case reports describing an adverse event following the administration of Tc-99m macrosalb were found but did not include an allergic reaction [4-6]. To the best of our knowledge, this is the first case report describing an anaphylactic reaction due to a Tc-99m macrosalb injection.

\section{Case Presentation}

A 49-year-old woman was referred for a lung perfusion scan because of possible chronic thromboembolic pulmonary hypertension as a result of a previous pulmonary 
embolism. The patient has a medical history of heterozygosity for the prothrombin gene, Hemolysis Elevated Liver enzymes and Low Platelet count (HELLP) syndrome, as well as having had a stroke during pregnancy, mastitis, melanoma, pneumonia and pulmonary embolism. The concomitant medication used was rivaroxaban at $20 \mathrm{mg}$ per day with a target international normalised ratio (INR) $>2.5$ and oxycodone $5 \mathrm{mg}$ when required for the relief of migraine attacks. As far as we know, the patient did not use over-the-counter products at the time of this adverse event.

With an estimated weight of $70 \mathrm{~kg}$ and height of $160 \mathrm{~cm}$, the patient received an intravenous (IV) injection of Tc-99m macrosalb $120 \mathrm{MBq}$, containing macroaggregates of human albumin $0.14 \mathrm{mg}$, according to protocol. Within $1 \mathrm{~min}$ after the injection she developed itching all over the body, including an itching throat and dyspnoea. Subsequently, within a period of $5 \mathrm{~min}$, urticaria emerged. Fifteen minutes after the administration of Tc-99m macrosalb, the patient was transferred to the emergency room. Upon examination the patient had facial oedema, especially around the eyes. The left eye showed some redness and the patient still experienced slight dyspnoea. The emergency doctor diagnosed an anaphylactic reaction, without hemodynamic involvement. The patient was diagnosed with a type I allergic reaction. The patient received clemastine $2 \mathrm{mg}$ IV and prednisone $25 \mathrm{mg}$ IV. Approximately 2 or $3 \mathrm{~h}$ after administration of Tc-99m macrosalb, the symptoms improved. The patient was released from hospital upon recovery and was given clemastine $1 \mathrm{mg}$ twice daily when required. She was contacted a few days later, and a full recovery was confirmed.

The patient had experienced a similar reaction, approximately 20 years ago, to a combination of acetaminophen, propyphenazone and caffeine (Saridon ${ }^{\circledR}$, Bayer B.V., the Netherlands), which was used to treat headache. Furthermore, she reported a similar reaction after an injection with a contrast medium used for a CT scan some years before the reaction to Saridon ${ }^{\circledR}$.

\section{Discussion}

To establish the frequency of adverse events following Tc$99 \mathrm{~m}$ macrosalb administration, we analyzed the number of doses dispensed (since 2011) at the Zwolle Radiopharmacy versus reported adverse events. Our data showed that this was a single reported case of anaphylaxis in 6778 doses dispensed for administration. This low frequency of adverse events is in line with what is described in the literature [7]. Furthermore, there are not many studies on this subject. Nevertheless, adverse events with radiopharmaceuticals might be underreported [7, 8].

Several mammalian and avian serum albumins (SAs) are known allergens [9], and a rare case of an allergic reaction to technetium-labelled nanocolloidal albumin for sentinel node identification has been described [10], but not for Tc-99m macrosalb. Although no laboratory tests were sent off for confirmation and a clinical rechallenge was not carried out, it is most likely that the anaphylaxis was induced by Tc- $99 \mathrm{~m}$ macrosalb, as the symptoms arose immediately following the injection. For this particular patient we could not determine a prior exposure to Tc$99 \mathrm{~m}$ macrosalb, although this cannot be ruled out. None of the patient's current medications could account for these hypersensitivity symptoms.

Table 1 Causality assessment of this case using the Naranjo algorithm [11]

\begin{tabular}{|c|c|c|c|c|c|}
\hline No. & Question & Yes & No & $\begin{array}{l}\text { Do not } \\
\text { know }\end{array}$ & $\begin{array}{l}\text { Score in this } \\
\text { patient }\end{array}$ \\
\hline 1. & Are there previous conclusive reports on this reaction? & +1 & 0 & 0 & 0 \\
\hline 2. & Did the adverse event appear after the suspected drug was administered? & +2 & -1 & 0 & +2 \\
\hline 3. & $\begin{array}{l}\text { Did the adverse reaction improve when the drug was discontinued or a specific antagonist } \\
\text { was administered? }\end{array}$ & +1 & 0 & 0 & +1 \\
\hline 4. & Did the adverse reaction reappear when the drug was readministered? & +2 & -1 & 0 & 0 \\
\hline 5. & $\begin{array}{l}\text { Are there alternative causes (other than the drug) that could on their own have caused the } \\
\text { reaction? }\end{array}$ & -1 & +2 & 0 & +2 \\
\hline 6. & Did the reaction reappear when a placebo was given? & -1 & +1 & 0 & 0 \\
\hline 7. & Was the drug detected in the blood (or other fluids) in concentrations known to be toxic? & +1 & 0 & 0 & 0 \\
\hline 8. & $\begin{array}{l}\text { Was the reaction more severe when the dose was increased, or less severe when the dose } \\
\text { was decreased? }\end{array}$ & +1 & 0 & 0 & 0 \\
\hline 9. & $\begin{array}{l}\text { Did the patient have a similar reaction to the same or similar drugs in any previous expo- } \\
\text { sure? }\end{array}$ & +1 & 0 & 0 & 0 \\
\hline 10. & Was the adverse event confirmed by any objective evidence? & +1 & 0 & 0 & +1 \\
\hline Total score & & & & & 6 \\
\hline
\end{tabular}


The timing between administration of the drug and the start of the symptoms, as well as the fact that this adverse drug reaction is mentioned in the Summary of Product Characteristics (SmPC), is suggestive of a causal relation. We performed a causality assessment using the Naranjo algorithm. The Naranjo algorithm uses ten questions that are scored. The sum of the score gives an indication of probability [11]. The results-using this causality assessment method-are presented in Table 1. A Naranjo assessment score of 6 was obtained, indicating that the relationship between the allergic reaction and the administration of Tc-99m macrosalb should be considered as 'probable'. The outcome 'probable' was assigned since the allergic reaction reasonably correlated with time of onset of the reaction, improved after withdrawal of Tc-99m macrosalb and could not be ascribed to other characteristics of the patient.

The reaction could be caused by the active ingredient of Tc-99m macrosalb, namely macro-aggregates prepared from human serum albumin. Anaphylaxis has been described for human albumin used as volume substitutes [12-14]. In one study, an incidence of $0.011 \%$ was determined [13]. However, the amount of human albumin administered as volume substitutes is general much higher (in the order of whole grams) than the amount of Tc-99m macrosalb given (a fraction of a milligram). It could also be the case be that one of the excipients of the formulation caused the reaction. As far as we know, the patient had not previously been exposed to Tc-99m macrosalb or to one to its excipients, which would have been required for any prior sensitisation. Whether or not the anaphylaxis was caused by an allergic reaction or a non-immune mediated reaction is therefore not clear.

\section{Conclusion}

Anaphylactoid reactions to Tc-99m macrosalb may occur. Although rare, the possibility of such a reaction must be anticipated. Healthcare professionals should check if a patient has had a previous severe reaction to Tc-99m macrosalb. Medical personnel should be prepared for these kind of reactions, and suitable protocols for managing and treating anaphylactoid reactions should be readily available.

\section{Compliance with Ethical Standards}

Funding No financial support was received for the conduct of this study or preparation of this manuscript.
Conflict of interest Nanno Schreuder is employed by GE Healthcare. Quincy de Hoog, Wouter van der Bruggen, and Eugène van Puijenbroek have no conflicts of interest that are directly relevant to the content of this case report.

Patient consent Written informed consent was obtained from the patient for publication of this case report. A copy of the written consent may be requested for review from the corresponding author.

Open Access This article is distributed under the terms of the Creative Commons Attribution-NonCommercial 4.0 International License (http://creativecommons.org/licenses/by-nc/4.0/), which permits any noncommercial use, distribution, and reproduction in any medium, provided you give appropriate credit to the original author(s) and the source, provide a link to the Creative Commons license, and indicate if changes were made.

\section{References}

1. Summary of product characteristics MaaSol. Eindhoven: GE Healthcare; 2016. https://www.geneesmiddeleninformatiebank. nl/smpc/h16168_smpc.pdf. Accessed 19 Nov 2018.

2. Silberstein EB. Prevalence of adverse reactions in nuclear medicine. J Nucl Med. 1996;37:1064-7.

3. Silberstein EB. Prevalence of adverse events to radiopharmaceuticals from 2007 to 2011. J Nucl Med. 2014;55:1308-10.

4. Dworkin HJ, Smith JR, Bull FE. A reaction following administration of macroaggregated albumin (maa) for a lung scan. Am J Roentgenol Radium Ther Nucl Med. 1966;98:427-33.

5. Roberts HJ. Fatal hemoptysis in pulmonary embolism probably precipitated by pulmonary scanning. Report of a case and suggested precautions. Angiology. 1970;21:270-4.

6. Vincent WR, Goldberg SJ, Desilets D. Fatality immediately following rapid infusion of macroaggregates of $99 \mathrm{mTc}$ albumin (MAA) for lung scan. Radiology. 1968;91:1180-4.

7. Pinto SR, Santos LFC, Dos Reis SRR, Bastos MK, Gomes VDS, Vieira TO, et al. Adverse reactions to radiopharmaceuticals: a survey based on clinical cases using criteria of systematic review. Ther Innov Regul Sci. 2018;52:109-13.

8. Santos-Oliveira R, Machado M. Pitfalls with radiopharmaceuticals. Am J Med Sci. 2011;342:50-3.

9. Chruszcz M, Mikolajczak K, Mank N, et al. Serum albuminsunusual allergens. Biochim Biophys Acta. 1830;2013:5375-81.

10. Chicken DW, Mansouri R, Ell PJ, et al. Allergy to technetiumlabelled nanocolloidal albumin for sentinel node identification. Ann R Coll Surg Engl. 2007;89:W12-3.

11. Naranjo CA, Busto U, Sellers EM, et al. A method for estimating the probability of adverse drug reactions. Clin Pharmacol Ther. 1981;30:239-45.

12. Bertrand JJ, Feichtmeir TV, Kolomeyer N, et al. Clinical investigations with a heat-treated plasma protein fraction-Plasmanate ${ }^{\circledR}$. Vox Sang. 1959;4:385-402.

13. Ring J, Messmer K. Incidence and severity of anaphylactoid reactions to colloid volume substitutes. Lancet. 1977;1:466-9.

14. Paul K, Schlesinger RG, Schanfield MS, et al. Reaction to albumin. JAMA. 1981;245:234-5. 